\title{
JOVENS, ESCOLA E TRABALHO: SIGNIFICADOS E SENTIDOS ATRIBUÍDOS ${ }^{1}$
}

\author{
FERNANDES, Andrea da Paixão
}

\begin{abstract}
RESUMO
Este trabalho parte dos sentidos atribuídos por jovens, estudantes da modalidade Educação de Jovens e Adultos (EJA), às suas trajetórias escolares. Esses jovens reúnem a experiência de terem estudado em escola pública quando crianças, saído e retornado na EJA. Para analisar a relação estabelecida com o mundo do trabalho, partimos de questionário composto por perguntas abertas e fechadas. Investigamos a inserção desse grupo em atividades laborais e em quais condições isso ocorre (formal ou informal). Consideramos, também, as respostas atribuídas pelos estudantes às perguntas sobre os motivos de saída da escola e de retorno aos espaços escolares. Reconhecemos que a escola pública é significativa para eles e que o trabalho se apresenta como justificativa para os motivos de saída e de retorno. Sobre as condições de trabalho, a minoria está inserida no mundo do trabalho, contudo, em maioria, no contexto da informalidade.
\end{abstract}

Palavras-Chave: Juventude - Educação de Jovens e Adultos - Trabalho - Escola Pública.

\begin{abstract}
This paper investigates the meanings that students attending Young and Adult Education courses attribute to their learning paths. These youngsters gather their experience of having studied in public school as children, then left and returned to adult education. To analyze the relationship established with their work environment, we started out with a survey, which included open and closed questions. We investigated the insertion of this group in work activities and under what conditions (formal or informal) this occurred. We also considered the answers given by the students to questions regarding dropping out of school and then coming back. We gathered that the public school is meaningful to them and that having to work is a justifiable reason both for leaving and coming back. Regarding working conditions, very few are inserted in the labor market and, mostly, in informal conditions.
\end{abstract}

KEYWORDS: Youth - Young and Adult Education - Work - Public School.

\footnotetext{
${ }^{1}$ Este texto foi apresentado em Comunicação Oral no Seminário Internacional Brasil \& Portugal: Jovens, Subjetividades e Novos Horizontes, em setembro de 2012, no Rio de Janeiro, RJ.

2 Professora Adjunta da Universidade do Estado do Rio de Janeiro / Instituto de Aplicação Fernando Rodrigues da Silveira (CAp-UERJ). E-mail: andreaf@uerj.br.
} 


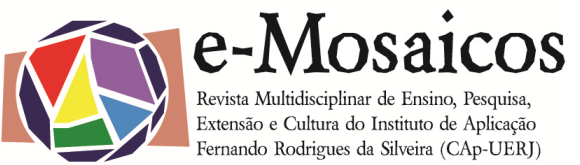

\section{DiÁLOGO INICIAL}

Em uma conversa sobre jovens, escola e trabalho algumas questões se apresentam. Para começar, quem é o jovem? Tentar responder a esta pergunta é basilar para se refletir sobre como o jovem interage e externa seus campos de interesse e de demanda no espaçotempo da escola. Associa-se a esse movimento a necessidade de, do lugar de educadores, compreender tensões e elaborar reflexões sobre as relações e (inter)ações que se configuram quando são considerados os jovens no espaço escolar.

Outra questão que considero importante para a reflexão sobre o jovem e a escola perpassa o cotidiano da modalidade Educação de Jovens e Adultos (EJA) e ganha espaço nos diálogos entre professores das escolas da EJA e que trazem em sua essência uma indagação consensual: como lidar com os jovens que chegam cada vez mais jovens na EJA?

Para essa construção reflexiva tomo por base, além dos referenciais teóricos escolhidos, levantamentos oriundos de pesquisa concluída recentemente que teve como sujeitos participantes estudantes da modalidade Educação de Jovens e Adultos de escolas públicas municipais cariocas ${ }^{3}$. 0 oIhar sobre a pesquisa e a partir dela permite, ainda, pensar sobre quem são os jovens que frequentam as escolas da EJA na atualidade e quais são as relações que estabelecem com o mundo do trabalho.

\footnotetext{
${ }^{3}$ Refiro-me à pesquisa de Doutorado de minha autoria intitulada "Memórias e Representações Sociais de Jovens e Adultos: lembranças ressignificadas da escola da infância e expectativas no retorno à escola", desenvolvida junto ao Programa de Pós-Graduação em Educação da Universidade Estadual de Campinas e concluída em 2012.
}

\section{QUEM É O JOVEM?}

O jovem não é o mesmo em todo o tempo e lugar. E o jovem de hoje, certamente, não é semelhante ao jovem de outrora. "Ser jovem" também se transformou com o tempo. Ainda que, de acordo com o pensamento sociológico, a conceituação de juventude tenha surgido na sociedade moderna ocidental e se desenvolvido durante 0 século XX (ABRAMO, 2005), o mundo e os contextos sociais nos quais o jovem do século XXI vive são diferentes dos contextos do século $X X$, embora esteja ali atrás, ainda tão próximo a nós. Em relação a esse fenômeno, Singer (2005) afirma que os jovens de hoje nasceram em contextos de crise social, o que pode ser comprovado pelos Censos Demográficos de 1960 e de 1970 que apresentaram índices de aumento da desigualdade.

O mundo em que vive a atual coorte de jovens é o resultado de uma evolução histórica que as coortes de seus pais e avós construíram. A história sempre é feita de coortes. Embora elas se misturem em festas ou comemorações cívicas, nas famílias e no trabalho, a história, em cada período, é o resultado de coortes de adultos e velhos que desfrutam de poder político e/ou econômico, sendo desafiadas e denunciadas por coortes de jovens que deles dependem. Este foi um fato comum nos séculos das revoluções, que começaram em 1789 com a Revolução Francesa e terminaram 200 anos depois, com a queda do muro de Berlim (SINGER, 2005, p. 28).

Paul Singer chama a atenção que os ciclos se repetem e, diante disso, com a juventude atual, o que acontece se assemeIha ao vivido no século XVIII. Com esses ciclos em que situações de empoderamento (ou não) econômico ficam concentradas nas mãos de pais, governantes, patrões e nas 


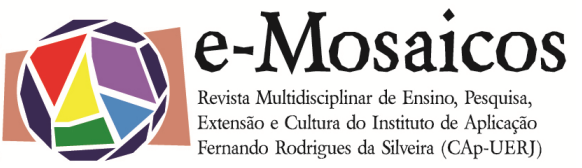

mãos dos próprios jovens, uns têm acesso a determinados bens culturais, econômicos e sociais, e outros não. Nesses casos, as condições de submissão de uns jovens a outros jovens ocorre. Com isso, a transitoriedade da juventude para a idade adulta apresenta tempos e contextos diferenciados.

Pais; Cairns; Pappámikail (2005) associa essa dificuldade de transição à ideia de "prolongamento da juventude", em que os marcos do final da juventude são variáveis de acordo com o universo cultural e socioeconômico nos quais se inserem. "A juventude é, nessa construção sociológica, uma categoria social cujas práticas e atitudes são estruturadas por um efeito cronológico de idade, apesar de distinções de gênero, de classe social e outras" (PAIS; CAIRNS; PAPPÁMIKAIL, 2005, p. 112).

Helena Abramo (2005) define o "ser jovem" e a juventude a partir da aparente obviedade do termo, mas ressaltando que quando se pretende aprofundar mais uma definição para o termo, torna-se de fato visível a sua imprecisão. Para a autora,

No debate sobre políticas de juventude que se instaura agora no Brasil, essa tensão entre uma impressão de obviedade e a dificuldade de definições mais claras também vigora. 0 termo nunca esteve tão presente nos discursos e nas pautas políticas, mas ainda permanecem uma grande indeterminação e muitas indagações a respeito do que, afinal de contas, está sendo designado por ele. Por que a juventude se torna hoje um tema relevante? Como se fundamenta a necessidade de políticas para esse segmento? 0 que constitui a juventude como singularidade ante outros segmentos populacionais? (ABRAMO, 2005, p. 38).

Um dos aspectos a serem considerados ao se definir a juventude e o "ser jo- vem" é que esta etapa da vida é marcada pela concepção de pluralidade e de diversidade que caracterizam a vida juvenil. No entanto, paradoxalmente, nem sempre a sociedade e a escola se dão conta dessa representação, ficando sua caracterização ancorada em um modelo idealizado de jovem e de juventude.

Dentre as leituras e imagens tecidas a respeito do "ser jovem" e da juventude está a percepção de que esta fase da vida humana traz em si uma condição transitória para a vida adulta. Dayrell e Carrano ${ }^{4}(\mathrm{~s} / \mathrm{d})$ reconhecem essa transitoriedade ressaltando ser uma concepção bastante presente na escola, a qual centrada nos possíveis projetos de futuro e na perspectiva do diploma tende a negar as experiências vividas pelo jovem no seu cotidiano e que, por sua vez, são carregadas da pluralidade e da diversidade que os faz jovens socialmente inseridos. As visões romântica, cultural e de crise juvenil, também são consideradas pelos autores como partícipes do rol de imagens e representações do "ser jovem" e da juventude. A visão romântica marca os anos sessenta do século $X X$, com as músicas, adornos, nova concepção de liberdade, de formas de expressão e de comportamentos. 0 mercado do consumo e as manifestações culturais são determinantes de cada época histórica e refletem as leituras de mundo feitas, também, pela juventude.

Dayrell e Carrano (s/d) chamam a atenção para o risco das tendências juvenis ficarem restritas aos finais de semana e, portanto, aos espaços outros que não a escola. Carrano (2000a, p. 13) afirma que "a forte presença cultural do sentido de juventude em nossas sociedades é geradora de representações sociais que, em muitos as-

\footnotetext{
4 Disponível em: www.fae.ufmg.br/objuventudes/ textos/jovens\%20Brasil\%20México.odf. Acesso em: 09/03/2010.
} 


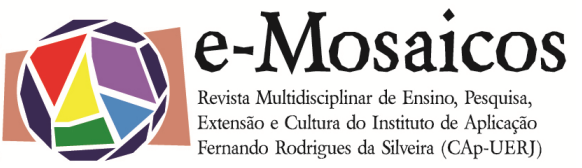

pectos, se afastam dos efetivos sentidos das práticas culturais produzidas pelos jovens". De acordo com esse autor, para se analisar o jovem e as suas formas de atuação na sociedade, precisa-se levar em conta a complexidade dessa sociedade e a indefinição do conceito de juventude, a qual permeia não só as determinações e as atribuições etárias, como ainda os direitos e deveres do jovem na escola, no mercado de trabalho e nos diferentes espaços e tempos sociais pelos quais transita, interage e se faz sujeito. Se juventude é um estilo de vida, esse estilo carrega a marca de situações que a identifica: maneiras de se vestir, adornos, músicas, ritmos, formas (ou não) de inserção no cenário político, etc. Esses aspectos contribuem, também, para a definição da transitoriedade da juventude entre as formas de inserção e de se fazer na teia complexa da sociedade, e os processos de crise que tendem a marcar essa faixa etária. Então, a que se refere à chamada crise juvenil? Qual é o papel da escola, da família e do mundo do trabalho na orientação dos jovens?

Se a singularidade e a pluralidade são duas características do "ser jovem", é acertada a proposição de que precisam ser pensadas políticas específicas para a juventude. Para isso, portanto, é necessário entender essa fase da vida de forma social e representacional, que não é única e que, por esse motivo, precisa ter respeitadas as caracterizações e marcas que a definem em cada época.

Abramo (2005), ao analisar a necessidade de proposição de políticas públicas para este segmento social, destaca a importância de se considerar a diversidade de espaços de convivência da juventude, o que requer ações articuladas por diversas áreas, dentro de uma visão integral de sujeito, haja vista que são muitos os desafios que perpassam o "ser jovem". "Significa dizer que para compreender a juventude, seus desafios e impasses é necessário conhecer os grupos culturais em torno dos quais se articulam" (DAYRELL, 1999, p. 30). E necessário, ainda, conhecer os espaços onde podem ocorrer tais articulações, considerandose que esses espaços, na atualidade, estão carregados de novos sentidos que, por sua vez, propõem repensar os conceitos de pertencimento, territorialidade e temporalidade. A ideia de pertencimento não está mais fixada em um grupo específico, pois os sujeitos da sociedade atual transitam por diferentes espaços e grupos, podendo até mesmo fazer isso simultaneamente. $\mathrm{Da}$ mesma forma, esses movimentos não precisam estar ligados, necessariamente, a um território determinado e único. A temporalidade no contexto atual permite que grupos sejam formados e desfeitos; reelaborados; reestruturados de acordo com as demandas de cada momento.

\section{6),}

Conforme afirma Cordeiro (2009, p.

Ser jovem, muito além de uma experi-
ência geracional, diz respeito a viver
múltiplos pertencimentos (na escola,
no trabalho, na igreja, por exemplo); é
estar permanentemente em trânsito
nessas experiências de vida, sendo a-
travessado e constituído pelas condi-
ções concretas de vida.

No cenário da participação na vida política do país, a juventude também se fez e se faz representar. Exemplo disso são os movimentos da década de 1960, 1980 e 1990 que contaram com a participação dos estudantes, contribuindo para escrever a história mais recente do país. Esses movimentos, representados, majoritariamente, por jovens, deram visibilidade à participação da sociedade civil na luta por direitos e interferem diretamente na garantia de direitos subjetivos a essa parcela da população. 


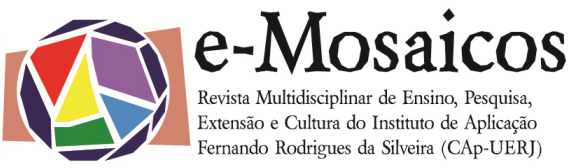

Gaudêncio Frigotto chama-me também a pensar sobre a questão da juventude em pesquisa desenvolvida, apropriando-se da expressão "vida provisória e em suspenso". Cunha tal expressão de Victor Fraenkel, psicólogo que foi preso pelo governo Hitler e que estabelecia comparações entre a situação em campos de concentração, os que viviam em sanatórios em tratamento de tuberculose e os desempregados, ou seja, pessoas que viviam em situação psicossocial de provisoriedade e, portanto, em condição de vida provisória e em suspenso. À luz do conceito e da caracterização do sistema capitalista, Frigotto ressalta o agravamento ainda maior do cenário em suspenso em que se encontra a vida de parcela da população brasileira na atualidade.

Assim como Frigotto, considero que - capitalismo gera tais agravamentos ao radicalizar o trabalho precário, informal ou temporário e ao promover a super exploração pelo trabalho. Junta-se a esse contexto o quadro do analfabetismo, estimulando mais ainda a situação de provisoriedade no cenário brasileiro. Quando se trata $\mathrm{da}(\mathrm{s})$ trajetória(s) das juventudes, tal situação é marcada por mais precariedade ainda. É nesse contexto que Frigotto (2009) considera a "juventude com vida provisória e em suspenso". Ganha espaço, aqui, a vulnerabilidade que acompanha o ser jovem.

No cenário brasileiro em que as políticas públicas para juventude ainda não têm as marcas de algo que caminha com luz própria, entendo que as juventudes encontram-se numa situação de vida provisória e em suspenso. Chego a esse entendimento por considerar relevante a denominação juventudes ${ }^{5}$ atribuída por Juarez Dayrell e

\footnotetext{
5 Frigotto (2009, p. 115-116) também concorda com o uso da terminologia juventudes ao afirmar que "a tentativa de uma definição unívoca de juventude, mesmo no critério restrito de uma fase geracional e biológica da vida, é complexa. Mais ainda quando o
}

por Paulo Carrano e também corroborada por Frigotto, que consideram a pluralidade e a multiplicidade existente na categoria "ser jovem".

A necessidade imposta nessas décadas recentes de se planejar e propor políticas para a juventude é real e faz parte de um movimento que precisa considerar uma série de aspectos que compreendem: as diversidades e especificidades que caracterizam essa fase da vida; a percepção de situações de vulnerabilidade que atingem a juventude; as formas e representações do "ser jovem" na sociedade; dentre outros. Considera, ainda, uma parcela da população jovem que é alvo das políticas públicas que se materializam por programas, projetos, ações de ordem social e educacional, observação esta também realizada por Frigotto (2009). Entendo que, a considerar todos esses aspectos, rompe-se com uma visão homogeneizante do conceito de juventude e começa-se a entendê-la e a percebê-la como um processo em construção na sociedade. É essa compreensão que me permite pensar as juventudes, no plural, com suas múltiplas identidades e formas de identificação em diferentes tempos e contextos.

$\mathrm{Na}$ teia da complexidade das sociedades, as marcas das fases da vida e, como parte dela, das juventudes, não mais estão contidas em definições puramente biológicas. Conceitos, especificações e as relações entre jovens e adultos se metamorfosearam através dos tempos. Esse movimento leva alguns adultos a afirmarem que os jovens parecem viver em outro mundo, é caracterizado pelos "novos" valores, culturas, formas de ver e de estar em um mundo marcado pela complexidade.

tema se desdobra no âmbito econômico-social e cultural. Mais adequado seria, talvez, falar, como vários autores indicam, em juventudes, especialmente se tomarmos um recorte de classe social". 


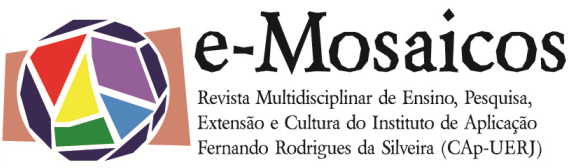

Tais aspectos possibilitam compreender que as trajetórias escolares e as interrelações com a instituição escolar e com outros sujeitos que a povoam precisam ter as marcas desses novos tempos e das novas formas de ver e de estar no mundo. Escola e família necessitam, consequentemente, estarem atentas a essas mudanças na tessitura social, para que sejam capazes de orientar os jovens em suas escolhas.

\section{JOVENS, PROMESSAS E ESCOLA}

A necessária democratização do acesso à educação, que se conjuga à abertura das portas da escola às massas, atende muito mais a uma demanda do modo de produção do que se realiza a partir de uma reestruturação organizacional e pedagógica das instituições escolares visando uma oferta educacional coerente com as demandas de seu "novo público". A escola continuou a mesma, possibilitando a ampliação do modelo dual que fora, desde então, promotor de desigualdades e, por que não, de injustiças. Isso perdurou décadas, mas as escolas se apresentaram, de acordo com a visão de Canário (2005) em diferentes fases: "escola das certezas", "escolas das promessas" e "escolas das incertezas". Considerarei neste artigo a última fase denominada por Canário.

Desde fins do século $X X$, avançandose para o começo do século XXI, torna-se visível no cenário brasileiro e no contexto das reflexões sobre a escola, o que Rui Canário categorizou como "escola das incertezas". Considero extremamente necessário dialogar com as incertezas produzidas para que seja possível construir uma concepção de escola que aponte para a superação da dualidade estrutural que a acompanha historicamente.

Cabe ressaltar que a juventude é afetada pelas desesperanças que a marcam e que são caracterizadas pelas desigualdades sociais e econômicas que se tornam latentes no cenário de globalização e de instabilidade econômica que se apresentou nas décadas finais do século passado. É fato, portanto, que o novo modelo ou reconfiguração do cenário histórico, político e econômico das sociedades ocidentais aponta para a obsolescência das escolas, tendo em vista que estas ainda não conseguem acompanhar os avanços tecnológicos e de comunicação que perpassam as sociedades. Além disso, a escola, tal como existe em sua maioria, não atende aos interesses da juventude e se perde na lógica da produtividade e da certificação as quais, por sua vez, não vieram a garantir a promessa de empregabilidade.

\begin{abstract}
O efeito conjugado da expansão dos sistemas escolares e das mutações no mundo do trabalho tende a acentuar a discrepância entre o aumento da produção de diplomas pela escola e a rarefacção de empregos correspondentes. É esta evolução, da qual decorre um processo de desvalorização dos diplomas escolares, que permite falar da passagem de um "tempo de promessas" para um "tempo de incertezas" (CANARIO, 2005, p. 84).
\end{abstract}

No movimento onde predomina a incerteza, encontra-se a era da globalização do capital, com a liberalização dos mercados, privatizações nos setores de serviços, diminuição das proteções sociais. Esse novo tempo de fins do século XX e começo do século presente marca a destruição do estado de bem-estar social, com promoção de situações de exclusão social que podem ser vistas no mundo do trabalho, nas situações de moradia e de vida das pessoas.

As contradições entre os que têm emprego e os que estão subempregados ou excluídos do mercado de trabalho configuram modalidades de dualização social que estão associadas a uma 
crescente incapacidade reivindicativa por parte dos assalariados e a uma crescente fraqueza das instâncias sindicais (CANÁRIO, 2005, p. 85).

Esse movimento de globalização também tem seus efeitos nas possibilidades de acesso e de permanência das pessoas às escolas.

É com o processo de democratização e massificação da escola que é possível assinalar o ponto de viragem que marca o irreversível rompimento do equilíbrio que caracterizava a "escola das certezas" e a evolução para uma dupla perda de coerência da escola (CANÁRIO, 2005, p. 85).

Os estudos de Rui Canário e também os de José Machado Pais permitem afirmar que as incertezas existentes no cenário português são observadas e vivenciadas também no cenário brasileiro.

Em relação à juventude brasileira, tal como Portugal, o Brasil também (con)vive com os cenários duvidosos e incertos em fins do século $X X$, estendendo-se pelas duas primeiras décadas do século XXI. Pais (2001), em pesquisa realizada com jovens portugueses, confirma que os jovens vivem em um cenário instável e incerto, visto que a promessa de empregabilidade não é consequência direta do processo de escolarização. Pelo contrário, os jovens não estão se empregando, porque não há empregos para todos. Esta situação provoca a necessidade de que os trabalhos precarizados se multipliquem e que a escola funcione como "um parque de estacionamento" (PAIS, 2001) de desempregados em potencial.

Contudo, essa massa que se constitui de jovens sem emprego não é suficiente para mostrar que há um crescimento do desemprego para essa parcela da popula- ção. Os estudos portugueses apontam que a taxa de desemprego no começo da década de 2000, na população de 15 aos 29 anos, tem reduzido. No Brasil, estudos de Marília Sposito (2003) apresentam que, dentre a faixa da população economicamente ativa, o desemprego na população juvenil em 2001 chega à casa de $27,3 \%$ para a população entre 15 e 19 anos e a 18,9\% entre a população de 20 a 24 anos. Comparando com o começo da década de 1990, o mesmo estudo indica que a taxa de desemprego na população brasileira compreendida dos 15 aos 17 anos era de $13,7 \%$ e entre os 18 e 24 anos era de $11 \%$. É notável um aumento na tendência ao desemprego no mesmo período em que se tende a aumentar a frequência à escola.

Lendo a realidade brasileira e a portuguesa é possível reconhecer que, na verdade, a taxa de desemprego juvenil não diminuiu; o que ocorreu foi o aumento da escolarização dos jovens. Com a população juvenil permanecendo mais tempo na escola, reduz-se a busca por emprego e, por conseguinte, reduz-se também (ou mascaram-se) os índices de desemprego juvenil. Além disso, José Machado Pais em sua análise sobre o contexto português considera que há outro fator a ser pensado: além da falta de emprego para todos, a qualidade do trabalho é pior nos tempos presentes e sua precariedade cada vez maior.
A realidade da desocupação ou da o- cupação precária transformou as rela- ções da juventude com o sentido do trabalho, gerando muitas incertezas. Diante da baixa capacidade da econo- mia brasileira em gerar postos de tra- balho, resta aos jovens, principalmente das camadas mais pobres, os setores de serviços básicos (limpeza, seguran- ça, garçom, etc.), muitas vezes postos não assalariados ou sem registro for- mal. Assim, a escassez de empregos torna os jovens um dos principais seg- 
mentos da população ativa mais fragilizados (SOUSA, 2004, p. 52).

Estudos de ABRAMO ${ }^{6}$ (2005) apontam que a relação com o mundo do trabalho supera a relação com a escola, entretanto não permite afirmar com segurança que a inserção dos jovens no mundo do trabalho está condicionada à necessidade extrema de sobrevivência familiar. Não se pode negar que essa situação se faz mais presente para os jovens de camadas mais necessitadas economicamente. Por outro lado, entre os jovens em que sua participação no trabalho não está condicionada à sobrevivência familiar, sugere-se haver retenção de parte do que recebe para suas despesas pessoais, apontando-se assim para o trabalho como condição para a independência, ainda que esta seja parcial. Observa-se, assim, duas vertentes da entrada dos jovens no mundo do trabalho: a necessidade vital e o desejo de começar a construir mais autonomia com relativa independência. Conforme a autora

\begin{abstract}
as variações não são muito grandes, mas a ideia do trabalho como necessidade cresce com a idade, talvez mesmo em razão dos encargos que aparecem para parcela dos que estão nessa faixa etária (com casamento e filhos). E cai conforme aumenta a renda familiar [...] o que reforça a tese de que a "qualidade" do trabalho encontrado varia muito com a classe social (ABRAMO, 2005, p. 54).
\end{abstract}

Branco (2005) ressalta que os jovens têm procurado ocupação. Para ele, se isso não estivesse ocorrendo, ou seja, se a participação da juventude fosse somente nas

\footnotetext{
6 Faço referência aos resultados da pesquisa "Perfil da Juventude Brasileira" que consistiu em um levantamento quantitativo sobre os jovens em escala nacional. Ver: Abramo; Branco (2005).
}

atividades escolares e de aprendizagem profissional, os índices de desemprego no Brasil seriam mais reduzidos, pois ingressariam nas atividades laborais mais tardiamente. No entanto, a necessidade de sobrevivência individual e/ou familiar os empurra para a busca por trabalho, a qual nem sempre se materializa na perspectiva formal, além do comprometimento que tende a ocorrer na trajetória escolar dos que necessitam precocemente ingressar no mundo do trabalho.

Segundo dados do Censo Demográfico de 2010 (IBGE), são 34.236.060 os jovens brasileiros compreendidos pela faixa etária de 15 a 24 anos. Em relação aos dados de emprego, se for considerado o grupo de 15 a 17 anos 23,4\% estão desempregados, enquanto que no grupo compreendido entre 18 e 24 anos 16,6\% encontram-se nesta situação. De acordo com a PNAD/2009, a maior taxa de desocupação encontra-se na faixa etária de 15 a 17 anos. A análise dos desocupados segundo esta mesma pesquisa indica que $42,2 \%$ desses encontram-se entre 16 e 24 anos (PNAD/2009). ${ }^{7}$

\section{UM OLHAR SOBRE JOVENS ESTUDANTES DA EJA EM ESCOLAS MUNICIPAIS CARIOCAS}

A pesquisa que dá origem a este texto foi desenvolvida em turmas de educação de jovens e adultos das escolas municipais cariocas que estudaram em escola pública quando crianças e adolescentes e saíram da

\footnotetext{
7 O fato de haver variações entre faixas etárias em alguns dos recortes apresentados pela PNAD e pelo Censo Demográfico gera, em algumas situações, dificuldades ou mesmo impossibilidades de comparação de tais dados. Exemplo disso é o fato da PNAD/2009 apresentar os dados dos jovens desocupados por cada faixa - 15 a 17 e 18 a 24 anos - ou totalizadas, compreendendo-se a faixa de 16 a 24 anos. Para esta faixa a Síntese dos Indicadores 2009 indica que $17,7 \%$ desses jovens são desocupados.
} 


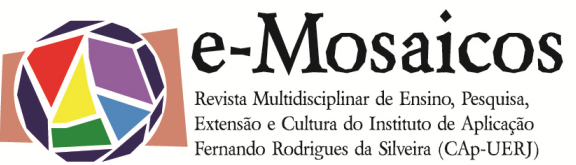

escola para, tempos depois, retornarem a ela. No recorte ora escolhido o foco é o jovem estudante da EJA.

Duas das perguntas feitas no questionário aplicado aos estudantes participantes da pesquisa foram: (1) Você trabalha? e (2) Se trabalha: Possui carteira assinada? E autônomo? Trabalha por conta própria? Faz biscate? Dentre a totalidade dos jovens e adultos identifica-se que $55 \%$ são trabalhadores. No entanto, dentre os jovens de 15 a 24 anos, 34\% se autodeclararam trabalhadores (gráfico 1).

\section{Gráfico 1 - Relação com o trabalho en- tre a população jovem pesquisada, em números absolutos e percentuais.}

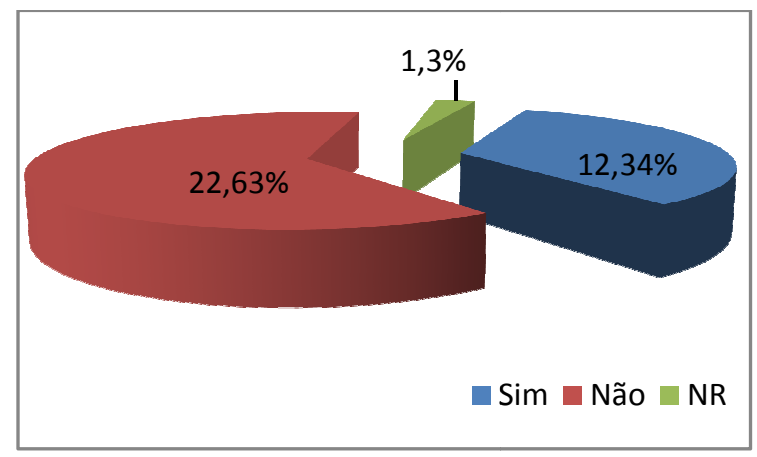

Considerando estritamente esses jovens que se autodeclararam trabalhadores, somente $34 \%$ o fazem com carteira assinada, ao passo que $33 \%$ reúnem os que trabalham por conta própria ou autonomamente $^{8}$ e $22 \%$ fazem biscates ${ }^{9}$ (gráfico 2 ).

\footnotetext{
${ }^{8}$ No decorrer da leitura dos questionários, percebi que não houve, por parte dos estudantes participantes da pesquisa, plena compreensão do que é o trabalhador autônomo e aquele que trabalha por conta própria, sem pagar por sua autonomia, apesar dos pré-testes realizados nos instrumentos não terem permitido reconhecer esta dificuldade. Optei, na análise dos dados, pela junção entre essas duas opções, uma vez que tal alteração não interfere na análise principal da pesquisa. Considera-se, no Rio de Janeiro, trabalhador por conta própria aquele que tem o trabalho certo,
}

\section{Gráfico 2 - Condição de trabalho espe- cificamente entre a população jovem pesquisada, que declarou trabalhar, em números absolutos e percentuais.}

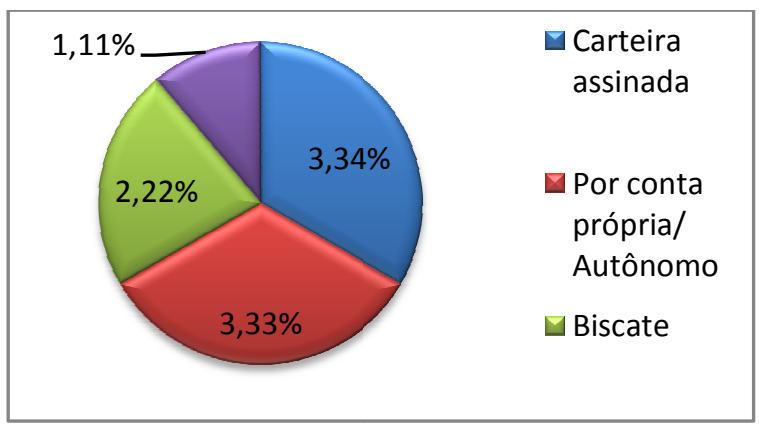

Os dados revelam que, embora sejam minoria os jovens que se autodeclararam trabalhadores nesta pesquisa, a maioria se insere de forma precária no mundo do trabalho (55\%). Compreende este grupo os que trabalham por "biscate" e os que têm trabalho certo, mas "por conta própria ou autônomo", como o que trabalha fazendo pipas ou como artesão, conforme declaração de estudantes. Assim, utilizam-se de estratégias diferenciadas para sobreviverem, mesmo com trabalho de baixa qualidade e precário.

Outras duas vertentes analisadas pela pesquisa - os motivos que os levaram a deixar a escola pública quando crianças ou adolescentes e a retornarem a ela mais tarde - apresentam o trabalho como categoria temática que surge significativamente para explicar esses movimentos, direta ou indiretamente nos discursos produzidos pelos jovens.

Ao serem perguntados "Por que, na-

\footnotetext{
todo dia desempenhando uma mesma função, mas não possui carteira assinada. Ele é diferente do biscateiro, conforme explicado na nota anterior.

${ }^{9}$ No Rio de Janeiro, denomina-se biscateiro aquele que não tem trabalho certo. O sujeito que faz um biscate é aquele que trabalha com o que aparecer, para receber um dinheiro.
} 


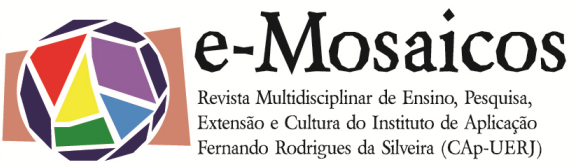

quela época, você saiu da escola?", considerando-se as cinco palavras ou expressões mais frequentes, após aproximações temáticas das respostas originalmente atribuídas pelos jovens, foi possível construir o seguinte quadro categorial-temático:

\begin{tabular}{|l|l|}
\hline $\begin{array}{c}\text { CATEgORIA } \\
\text { TemÁtICA }\end{array}$ & \multicolumn{1}{c|}{ SubCATEgoria } \\
\hline TRABALHO & Para trabalhar (8) \\
\hline APRENDER & Dificuldade de aprender (3) \\
\hline ESCOLA & $\begin{array}{l}\text { Desinteresse (7) } \\
\text { Mudança / migração para a } \\
\text { cidade grande (3) }\end{array}$ \\
\hline $\begin{array}{l}\text { QUESTÕES } \\
\text { FAMILIARES }\end{array}$ & Questões particulares (4) \\
\hline
\end{tabular}

As categorias temáticas trabalho, aprender, escola e questões familiares remetem às lembranças do passado escolar, ainda que, para alguns desses jovens estudantes, recentes. A organização das subcategorias, por sua vez, retratam correlações existentes com as categorias temáticas propriamente ditas.

Nesse percurso, a subcategoria "para trabalhar" contribui para a confirmação do trabalho como eixo temático forte e significativo para o grupo pesquisado, permitindo refletir sobre os motivos de saída do espaço da escola pública e sobre o quanto é significativa a necessidade de sobrevivência como motivo de saída da escola, de forma a que, por meio de algum trabalho, possam contribuir financeiramente com a família.

A categoria aprender se manifesta nas respostas atribuídas por esses jovens pelo viés da "dificuldade de aprender". Soma-se a esse, outro aspecto sério nos movimentos de idas e vindas de estudantes das salas de aula, apresentado pela categoria escola. Trata-se da subcategoria "desinteresse". Ambos parecem caminhar no mesmo sentido para quem não encontra na escola o seu porto seguro e compartilham de um mesmo movimento: o de não se sentir parte daquele espaço, ou seja, da escola. No entanto, entendo que a dificuldade de aprender não é o único fator que gera desinteresse dos jovens pela escola. Há outros que se somam e que desafiam os educadores e os sistemas de ensino a projetarem outras possibilidades de diálogo do mundo da escola com o mundo lá de fora, trazendo para dentro de seus muros contextos reais que, articulados aos saberes de cada um, possam produzir conhecimentos.

Ainda relacionado à categoria escola, a "mudança / migração para a cidade grande" se apresenta como justificativa para a saída, assim como "questões particulares", que, por inferência, classifico como sendo aquilo que o estudante não quis revelar, se insere na categoria questões familiares.

O grupo pesquisado tem como perfil ter estudado em escola pública e retornado a ela. Nesse contexto, a pergunta "Por que voltou para a escola?" traz um leque de revelações que permitem ser analisadas de acordo com uma visão de esperança, como pode ser observado no quadro a seguir, também se considerando as cinco maiores frequências de repostas em torno das categorias temáticas trabalho, aprender, questões familiares, projeção no futuro.

\begin{tabular}{|l|l|}
\hline $\begin{array}{c}\text { CATEgORIA } \\
\text { TEMÁTICA }\end{array}$ & \multicolumn{1}{|c|}{ SUbCATEgORIA } \\
\hline TRABALHO & $\begin{array}{l}\text { Emprego/emprego melhor (3) } \\
\text { Atualizar-se (2) }\end{array}$ \\
\hline APRENDER & $\begin{array}{l}\text { Concluir estudos (5) } \\
\text { Aprender mais (4) }\end{array}$ \\
\hline $\begin{array}{l}\text { QUESTÕES } \\
\text { FAMILIARES }\end{array}$ & Para ajudar os filhos (3) \\
\hline $\begin{array}{l}\text { PROJEÇÃO NO } \\
\text { FUTURO }\end{array}$ & $\begin{array}{l}\text { Ser alguém na vida/futuro } \\
\text { melhor (13) } \\
\text { Sonho a realizar (3) }\end{array}$ \\
\hline
\end{tabular}




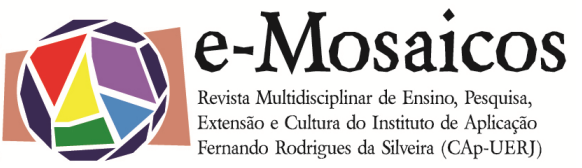

Associada à categoria trabalho encontram-se as subcategorias "emprego/emprego melhor" e "atualizar-se", ainda que suas frequências sejam as menores das cinco. Todavia, isso não Ihes retira a importância da revelação da escola como caminho para conquista de um emprego e, com ele, de perspectiva de um futuro melhor, conforme revelado na subcategoria "ser alguém na vida/futuro melhor", com a maior das frequências, e que, na análise, foi associada à categoria projeção no futuro. Também se associa a essa categoria "sonho a realizar", permitindo inferir que a esperança depositada nos processos de escolarização agora retomados pelo retorno à escola articulam, quase que metaforicamente, o sonho de um futuro promissor e, com ele, o ingresso no mundo do trabalho.

As subcategorias "concluir os estudos" e "aprender mais" depositam na escola a expectativa de aprender. Assim como precisa ser considerada a articulação existente com a subcategoria "para ajudar os filhos" que vêm atender, de acordo com os discursos revelados, às questões familiares. Os jovens que atribuíram essas respostas à pergunta "Por que voltou para a escola?" se consideram responsáveis por contribuir com os processos de aprendizagem de seus fiIhos e, para tal, necessitam, também estudar, conforme revela a estudante de 22 anos: "Aí eu tive que voltar porque meus filhos estudam e eles precisam, então eu tive que aprender porque eles precisam".

\section{RefleXões SOBRE OS Significados E SENTIDOS ATRIBUÍdOS}

Se, por um lado, o principal motivo de saída desses jovens da escola foi a necessidade de sobrevivência e de trabalho, por outro, o retorno para a escola da EJA é carregado de esperança, apresentando como expectativa do retorno à escola outra expectativa: a de um futuro melhor conjugada à realização de sonhos.

Ouso inferir e afirmar que a escola é, potencialmente, espaço de formação e onde conquistas para a vida são asseguradas. Mesmo com toda crise do mundo do trabaIho e não sendo mais, necessariamente, garantia de empregabilidade, porque, nas palavras de Machado Pais (2001), a escola também pode se constituir, nos tempos recentes, como "parques de estacionamento", ainda se configura como parque de esperanças na nossa sociedade.

Conforme afirma Souza (2004, p. 59)

O desafio, hoje, parece ser o de encontrar os fios para tramar a continuidade, construindo uma experiência de tempo que possibilite passar pela variedade $\mathrm{e}$ pela mudança sem se perder. Os jovens vivem intensamente as contradições deste tempo, pois as incertezas próprias da idade são agravadas pelas incertezas desta época, tendo em vista que as referências para a compreensão do tempo - a medição pela máquina e a orientação finalista - dissolvem-se. Cada vez mais, convive-se com tempos marcados pela subjetividade, fragmentação e ritmos diferenciados.

Nessas tramas em que fios vão delineando os percursos, as incertezas características do "ser jovem" se confundem com a incerteza da escola desses tempos, em que a juventude parece buscar suas certezas e, ainda, com a possibilidade de essa escola se colocar de outra forma frente aos desafios: que assegure aos jovens maior possibilidade de se pensar e de se colocar frente ao mundo, sua imprevisibilidade e sua, por que não, precariedade.

A necessidade de se propor outro modelo de escola que se aproxime mais das demandas que o futuro-presente projeta na 
vida cotidiana é real. Para isso, a escola precisa ocupar-se da formação de seus estudantes, de forma a prepará-los para a vida, de acordo com os princípios da formação omnilateral (GRAMSCI). Essa concepção de escola também deve considerar a necessária interação entre a escola e a sociedade, desenvolvendo articulações entre ensinar e aprender que ponderem os saberes escolares e os saberes não escolares como espaçostempos de aprendizagens que sejam significativas; promover o trabalho escolar de forma prazerosa e pensar a escola tomando-se por referência um projeto societário que seja capaz de promover a libertação das pessoas de contextos de opressão.

\section{REFERÊNCIAS BIBLIOGRÁFICAS:}

ABRAMO, Helena Wendel. Condição juvenil no Brasil contemporânea. In: ABRAMO, Helena Wendel; BRANCO, Pedro Paulo Martoni (orgs.). Retratos da juventude brasileira: análises de uma pesquisa nacional. São Paulo: Perseu Abramo, 2005. p. 37-72.

BRANCO, Pedro Paulo Martoni. Juventude e trabalho: desafios e perspectivas para as políticas públicas. In: ABRAMO, Helena Wendel; . (orgs.). Retratos da juventude brasileira: análises de uma pesquisa nacional. São Paulo: Perseu Abramo, 2005. p. 129-148.

CANÁRIO, Rui. O que é a escola? um olhar sociológico. Porto: Ed. do Porto, 2005.

CARRANO, Paulo Cesar Rodrigues. Juventudes: as identidades são múltiplas: In: Movimento - Revista da Faculdade de Educação da Universidade Federal Fluminense: Juventude, Educação e Sociedade. no 1, maio/2000a. p. 11-27.
CORDEIRO, Denise. Juventude nas sombras: escola, trabalho e moradia em territórios de precariedades. Rio de Janeiro: Lamparina, FAPERJ, 2009.

DAYRELL, Juarez Tarcísio. Juventude, grupos de estilo e identidade. In: Educação em Revista. Belo Horizonte, $\mathrm{n}^{0}$ 30, dez/1999. p. 25-38.

Projetos societários em disputa no Brasil e a juventude com vida provisória. In: RUMMERT, Sonia; CANÁRIO, Rui; FRIGOTTO, Gaudêncio (orgs.). Políticas de formação de jovens e adultos no Brasil e em Portugal. Niterói: EdUFF, 2009. p. 109-124.

PAIS, José Machado. Ganchos, tachos e biscates: jovens, trabalho e futuro. Porto: Ambar, 2001

.; CAIRNS, David; PAPPÁMIKAIL, Lia. Jovens europeus: retratos da diversidade. In: Tempo Social. Revista de Sociologia da USP. V. 17, no 2, 2005. p. 109-140.

SINGER, Paul. A juventude como coorte: uma geração em tempos de crise social. In: ABRAMO, Helena Wendel; BRANCO, Pedro Paulo Martoni (orgs.). Retratos da juventude brasileira: análises de uma pesquisa nacional. São Paulo: Perseu Abramo, 2005. p. 27-35.

SOUSA, Filomena Carvalho. O que é ser adulto? As velhas e novas representações sociais sobre o que é ser adulto. In: Actas dos ateliers do V Congresso Português de Sociologia - Sociedades contemporâneas: reflexividade e acção. Universidade do Minho, Campus Gualtar, Braga, 12 a 15 de maio de 2004, p. 47-55. Disponível em: $<$ http://www.aps.pt/cms/docs_prv/docs/DP R4628ceabbe76c_1.pdf> . Acesso em 21 de fevereiro de 2010. 
SOUZA, Carmen Zeli Vargas de. Juventudes e contemporaneidade: possibilidades e limites. In: Ultima Década. n. 20, CIDPA Viña Del Mar. Jan 2004. p. 47-69.

Os jovens no Brasil: desigualdades multiplicadas e novas demandas políticas. São Paulo: Ação Educativa, 2003. 